\title{
Masking Traditions and Their Behavioral Functions in Accounting for Stability and Order: A Critical Exposition of Select Study of West, East and Central African Masks
}

\author{
K. C. Ani Casimir ${ }^{1,2}$, Orajaka Sussan Nwakego ${ }^{2,3}$, Emmanuel Umezinwa ${ }^{4}$ \\ ${ }^{1}$ Department of Philosophy, University of Nigeria, Nsukka, Nigeria \\ ${ }^{2}$ Institute of African Studies, University of Nigeria, Nsukka, Nigeria \\ ${ }^{3}$ Department of Music, University of Nigeria, Nsukka, Nigeria \\ ${ }^{4}$ Department of Music, Nnamdi Azikiwe University, Awka, Nigeria \\ Email: cepperngo@gmail.com, orajakalinus@gmail.com, emma2000@yahoo.com
}

Received 26 February 2015; accepted 16 March 2015; published 18 March 2015

Copyright (C) 2015 by authors and Scientific Research Publishing Inc.

This work is licensed under the Creative Commons Attribution International License (CC BY). http://creativecommons.org/licenses/by/4.0/

(c) (7) Open Access

\begin{abstract}
Development in Africa is both material and non-material; cultural and non-cultural regarding the modern state in Africa. One of the reasons why some Western aspects of development fail to work in Africa derive from the stubbornness of the indigenous people to let go of a tradition that has defined them and identified them as a cultural group. One of these defining traditions is the masking trends that account for the different masquerades and esoteric cultures that explain law and order in Africa. We will not go into why development plans fail in Africa; but by going into the masking traditions of Africans, we can understand why certain behaviors are exhibited by Africans that account for the clash of modernity and tradition. Since this is a paradigm seeking edition, we have gone on a brief study of the masking traditions of West, East and Central Africa with a view to understanding and appreciating their functions in their base societies. We gather that there is a preponderance of ancestral consciousness in all of the masks studied. For example, Mossi masks appear most frequently at funerals. Kuba masks are used by sorcerers to call upon primordial ancestors for purposes of social control. These functions of masking traditions reveal the desire to enforce law and bring about order in the society. They show that the role of the masquerade is within the same purview as the police of today and the involvement of spiritual "realities" bring about fear and reverence.
\end{abstract}

\section{Keywords}

Masquerade, Masking Traditions, Culture, Africa, Societal Stability, Law and Order 


\section{Introduction}

\subsection{A Philosophical Detour into Masking Tradition and Governance Values}

In Africa, mask is fundamentally a spiritual and metaphysical value before it transformed into a socio-cultural value that helps the African people to create their sense of what constitutes order, law, authority and the proper way people should be governed. Masks are the representation of the African ancestral origin and authority that account for what constitutes human value, worth and meaning. The spiritual ancestors are the source of life, order and continuity in any African community. Modern governance is seen as a material activity in which people come together to create what should be law and order; authority for such law and order derives from the constitution, written by the people. But sources of law, order and what constitutes the proper way to lead a society is derived from the anscestors represented by masks and a living masquerade culture. It is this very forceful presence of anscestors that was alluded to by Ejizu (1986: p. 2) below:

The invisible members, especially ancestors and spiritual beings are powerful and by far superior to human beings. Their reality and presence in the community are duly acknowledged and honoured among various traditional African groups. Neglect could spell disaster for human beings and the community. The invisible beings are represented by different kinds of symbols like carved objects, shrines and sacred altars. They may also be recalled in personal names given to children, especially in cases where particular ancestors or spirit beings are held to have reincarnated in individual children. The presence of the ancestors is particularly felt in traditional African community. They are believed to be benevolent and powerful representatives of the community in the "mbakuv" (spirit land). Their symbols and shrines are common features among most traditional West African groups. This includes carved ancestral stool among the Akan of Ghana and "okpensi" among the traditional Igbo. There are also the shrines of the "Muzimu” (ancestors) among the Baganda of Uganda. The reality and presence of spiritual members are equally acknowledged through several taboos found in many African communities. For example, women within the child-bearing age are bound to observe several prohibitions among the traditional Igbo. Such women run a serious danger of becoming childless if they flout such taboos, since it could result in scaring away souls of unborn babies that are believed to hover around homesteads and families wanting to incarnate in wombs of potential mothers.

\subsection{Masking Traditions and Normative Standards of Behaviour}

The area of morality is one powerful relevant avenue through which traditional African masking concepts are used to form people and reinforce in them the important idea and value of good behavior and harmonious community-living. With masks as communal values embodiments, every social group in Africa attempt to evolve its distinct ethical code to match its unique governance systems. Governance in traditional African starts with an inherited good behavior code from the anscestors passed on from generation to generation. Every society has its norms of acceptable behaviour, unacceptable behavior, taboos and societal prohibitions. Many traditional African groups have in addition, motivational features and incentives through which compliance to the norms of approved behavior and social ideals are encouraged. There are equally rituals of purification, as well as punitive measures that try to deter and curb the tendency to deviate. Masquarades equate and embody this normative standard of good behavior and good governance as they are seen as the ancestors who gave the laws in the first place. It is also used to bring deviants back to good behavior and orderly conduct.

\subsection{Masks as Source of Promoting Community-Living among Africans}

One good and essential article of belief in African traditional religions is the truism that a fundamental delicate equilibrium between everything in the universe, and the visible world in which the society and human beings exist. With the Creator, who created everything that exists and set them into place, traditional Africans basically view the universe as comprising basically two realms; the visible and the invisible realms. Human beings are the focus of attention as they are the ones who should cooperate with the spiritual beings to maintain harmony to maintain the delicate balance in the universe and keep the peace of the universe. This is what brings about the happiness and prosperity of individuals and the community.

Harmonious living is clearly a pivotal spiritual value given by masquerades and maintained by them. This is why Ejizu (1986: p. 5) connects the religious, the inititations, the rituals and the community ideal of harmonius 
living even in the modern state:

African traditional religions, which have been rightly referred to as the womb of the people's culture, plays a key role in the realisation of this all-important value among every traditional African group. Religion is central in inculcating in the promotion and realisation of harmonious inter-relationship among individuals and the community. In the traditional African background, religion is a most important aspect of life. It pervades and permeates all aspects of life and infuses the social, economic, political dimensions African with meaning and significance. But there are some more striking avenues through which the traditional religion helps the community to realise the community ideal of harmonious living. They include transmission of certain key religious ideas and beliefs, initiation practices, ritual activities, sacred symbol forms and vital public institutions.

It might sound odd, but the conflict created by the dissonance between the modern source of order and the practice of ancestral order represented by masks account for the reason(s) why Africans find it difficult to fully embrace the modern ways of governance. To resolve the crisis of governance in the African modern state. It may be necessary to study masking traditions and appreciate their metaphysical, social and ethical implications for the modern African society since the explanation of the material lies in the non-material. Making an adequate display of a study of masking traditions in Africa entails presenting an introductory defining parameter that would serve as the frame of reference for both writer and reader, as well as putting the assigned study under proper context.

Much also, the definition of "masking tradition", whose elemental words are "mask" and "tradition", would take on a much deeper meaning if it is understood that the inclusion of ritual in masking traditions as analyzed in African traditional theatre in some quarters gives its definition a variant fire. Evidence of this stance in views of African theatre is aptly examined in studies undertaken by African scholars on their own art forms and masks. A strong argument is put forward in the reasoning that ritual and theatre are symbiotic, relating not as mutually exclusive antipodes but developing into each other, depending on the prevailing circumstance, and, therefore, the imputation of religious tones only in association with ritual and the expectancy that the creation would evolve into some full drama devoid of elemental ritual beginnings may be seen as one side of a coin when a context involves also the imputation of aesthetics and theatre in mask performances that leaves or returns to either of both worlds of myth/ritual or drama/theatre.

Forming the building blocks for these stances are the evolutionary viewpoint motivated by MJC Echeruo's The Dramatic Limits of Igbo Ritual (Obiechina, 1978) and the other which ably checked the former into selfassessment in stride. This other stance is the relativist viewpoint marshaled by such forces as 00 Enekwe's Myth, Ritual and Drama in Jgbo land and Igbo masks: The Oneness of Ritual and Theatre.

Armed with this awareness, a working definition of "masking tradition"-which can be the social processes involved in mimicking real life situations and transferred stories with the use of symbolic avatars possessed by real persons - is understood in varied dimensions.

Masking traditions in Africa are, therefore, replete with mythical sprinkles and douses and in some instances cut off from original mythical garbs and adopted and modified to suit a policing or checking valve or to fill a need to bring about order in a society. Where they are wearing their original rituals, masks are seen as a heritage to which life-and-death seriousness is constantly attributed. To talk about the function of a masquerade is to pull up the curtains for its utilitarian importance to be revealed. For functionality, in the researcher's view, denotes usability.

Masquerades have many functions, yet they appear to cluster into particular categories. There are masks associated with rites of passage such as adolescents' initiations, other age-related ceremonies, and death. Masking in seasonal festivals and renewal rituals is associated with the earth's fertility and the path of the sun as it appears to us from Earth. In other masquerades, men play women, generally as the maiden, mother, and crone. Masks also evolved into theater as, for example, in ancient Greece or the Noh drama of Japan. Other masquerades celebrate the changes of the seasons, which are associated with renewal and fertility. The Corpus Christi masking festivals of Ecuador celebrate the fertility of Christ's body and its positive impact on the fertility of crops and the harvest. Musical bands play as the processions of masqueraders move through the streets of Pujili.

Within most masquerade festivals, only men play the roles of women, which fall into three categories: the maiden, mother, and crone. In general, men play women's roles, first because men monopolize the masking process, and second, in order to communicate to both sexes the kinds of behavior they believe are appropriate 
for women. Maringuila maidens in the masquerades in Michoacán, Mexico, represent idealized beauty and how young women should conduct themselves in public. A short review of scholarship will be done with the purpose of establishing as much as possible in a study of this nature the researches made to examine the functions of isolated masking traditions. Masking traditions and masquarades in these select African countries portray values of order, control, stability, continuity, law and governance in their traditional forms. However as could be seen below, as modern concept used in contrasting modern forms og law and order they suffer limitations of human rights violations as they come. These limitations of masking traditions in African should not be used to evaluate their cultural significance as an indigenous form of establishing traditional sources of value for order, control and stability.

\section{Review of Scholarship}

This study focuses on masking traditions of West, East and Central Africa. Although, the Yoruba Gelede is studied again for this study, a variant approach to the Gelede is advanced in Nunley (1996: p. 1782). To Nunley, for the Yoruba Gelede of West Africa and in some Latin American countries, men dress as mothers and convey, through the round forms of their costumes and masks, women's promise of fertility and ability to bring stability to society. The two-faced Gelede mask reminds participants that each person has an inner and outer self, and that it is the inner face that keeps the outer appearing cool and collected during stressful times.

A study for Malian masks and their functions has been done extensively and the masks of the Bambara people have been in the spotlight of these researches. The Bambara/Bamanaare the largest ethnic group in Mali. They have been well studied in comparison with most other Africanpeople. They occupy the central part, an area of savannah. The dry land makes life hard. They live principally from agriculture, with some subsidiary hunting and cattle rearing in the northern part of their territory. They uphold their ancient tribal customs against Islam and Christianity, although recently the Muslim faith has been spreading among them. Their cosmology is quite complicated. They excelled in three types of sculpture: stylized antelope headdresses, statues, and masks.

The N'domo or N'tomo is a unique example. "The Ntomo, a society of the as-yet uncircumcised children, is well-known in the West thanks to its beautiful masks. Ntomo cannot, however, be considered "universal" among the Bamana. It prevailed mainly in the Beledugu, Bamako and Mande areas, between the Niger and Barn rivers, in the Baninko, the Bendugu and the Minyankala. It still exists in many localities, although it has been altered under Muslim influence. Sometimes Ntomo initiation occurs even if the people are officially Muslim, but mask performances are becoming rare in some villages.

In his writings about the N'domo mask of the Bambara (as shown in Figure 1), Lange (2005: p. 265) says:

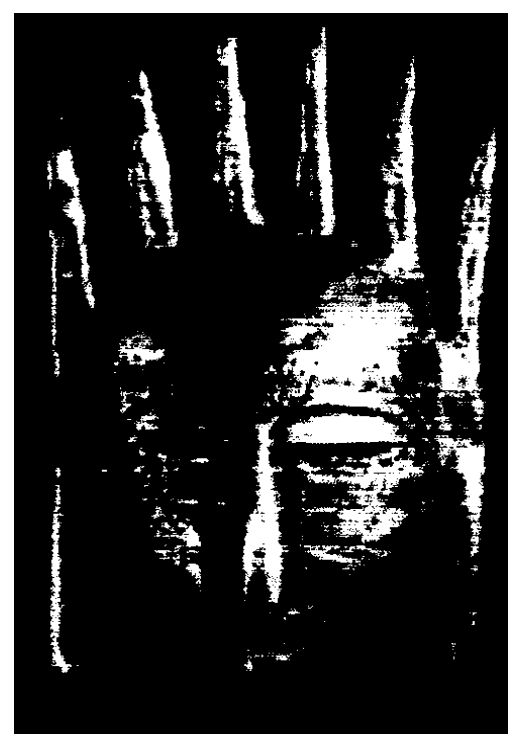

Figure 1. A variant showing the horns, common in many N'domo masks. 
The Bamana Ntomo masks were worn by boys as they passed through the early cycle of initiation into manhood. The masks reinforce the lessons the boys are taught as they are prepared by elder males in the society for circumcision. There are two main style groups of their masks. One is characterized by an oval face with four to ten horns in a row on top like a comb, often covered with cowries or dried red berries. The other type has a ridged nose, a protruding mouth, a superstructure of vertical horns, in the middle of which or in front of which is a standing figure or an animal. The ntomo masks with thin mouths underscore the virtue of silence and the importance of controlling one's speech. During their time in ntomo the boys learn to accept discipline. They do not yet have access to the secret knowledge related to korè and other initiation societies. Members wore a wooden face mask during the initiation festival at harvest time and when begging for rice. One reference says the number of horns on such masks to symbolizes a human being's levels of increased knowledge based on the initiation stages, while another reference sites that Ntomo masks with an even number of horns are female and those with an odd number of horns are male.

In the early 20th Century, artists like Pablo Picasso and Andre Derain were inspired by the bold abstract designs that they discovered in African tribal masks. They collected and used these works of art to influence their own style. In effect, they used African culture to refresh the tired tradition of figure painting in European art. (Cole, 1985).

To Cole (1985), African masks should be seen as part of a ceremonial costume. They are used in religious and social events to represent the spirits of ancestors or to control the good and evil forces in the community. They come to life, possessed by their spirit in the performance of the dance, and are enhanced by both the music and atmosphere of the occasion. Some combine human and animal features to unite man with his natural environment. Many African societies see masks as mediators between the living world and the supernatural world of the dead, ancestors and other entities. Masks became and still become the attribute of a dressed up dancer who gave it life and word at the time of ceremonies. In producing a mask, a sculptor's aim is to depict a person's psychological and moral characteristics, rather than provide a portrait. The sculptor begins by cutting a piece of wood and leaving it to dry in the sun; if it cracks, it cannot be used for a mask. African sculptors see wood as a complex living material and believe each piece can add its own feature to their work. Having made certain the wood is suitable, the sculptor begins, using an azde to carve the main features, a chisel to work on details and a rough leaf to sand the piece. He then paints the mask with pigments such as charcoal (to give a black colour), powders made from vegetable matter or trees (for ochre/earth tones) or mineral powders like clay (to give a white colour). African peoples often symbolize death by the colour white rather than black; at the same time, many African cultures see white as the colour that links them to their ancestors, and it can therefore have a positive meaning. The second face. Jam not myself The attributions of the origin of the objects is based on their stylistic and physical characteristics and/or on the data provided by the seller and/or experts, but of course certainty cannot be reached (Cole, 1985).

\section{Masking Traditions in Africa and Their Functions}

West Africa:

The Baule masks of Cote d'Ivoire and the Mossi masks of Burkina Faso will be examined.

\subsection{The Baule Masks}

The Baule people, known as one of the largest ethnic group in Cote d'Ivoire, have played a central role in twentieth-century Ivorian history. They waged the longest war of resistance to French colonization of any West African people, and maintained their traditional objects and beliefs longer than many groups in such constant contact with European administrators, traders, and missionaries. According to a legend, during the eighteenth century, the queen, AblaPoku, had to lead her people west to the shores of the Comoe, the land of Senufo. In order to cross the river, she sacrificed her own son. This sacrifice was the origin of the name Baule, for baouli means "the child has died." Now about one million Baule occupy a part of the eastern Côtedivoire between the Komoé and Bandama rivers that is both forest and savanna land (Jacques et al., 1988: p. 620).

\subsubsection{Baule Masking Tradition}

Baule art is sophisticated and stylistically diverse. Non inherited, the sculptor's profession is the result of a per- 
sonal choice. The Baule people use three major type of masks: the first is a helmet mask in the shape of a buffalo head, BonuAmwin; the second represents a human face with rounded, fairly realistic features; and the third type includes masks related to the Goli festival.

The BonuAmwin helmet mask (as shown in Figure 2) represents a buffalo's head with a pair of crescent-like flat horns, a T-shaped nose and a large rectangular mouth with exposed teeth-its stylized features inspired Picasso's costume designs. It is sometimes painted with black, white and red pigments. The mask was originally worn only by warring men. Nowadays, it is mostly used to protect villages. The second type of mask is characterized by a rounded face with realistic features, pointed chin, T-shaped nose, semi-circular eyes, raised scarification-typical of the Baule tribe - and an elaborate coiffure. They do not appear to have any sacred function and are worn only during festivities related to visits by important dignitaries. This type of mask sometimes has two faces, side by side, symbolizing twins, which for Africans is a good omen. The Goh festivities are held to celebrate new crops, the visits of dignitaries or periods of mourning. Three types of masks are used during these festivals: the first is of discoid shape and represents a highly stylized face beneath a pair of horns; the second is a helmet mask representing a buffalo head beneath antelope horns; and the third is used for closing the festivities, and has an elongated human face appearing under a pair of backward swept horns. Baule statues are usually standing on a base with legs slightly bent, with their hands resting on their abdomen in a gesture of peace, and theirelongated necks supporting a face with typically raised scarification and bulging eyes. The coiffure is always very detailed and is usually divided into plaits.

\subsubsection{Functions}

Wooden sculptures and masks allow a closer contact with the supernatural world. Baule figures answer to two types of devotion: one depicts the "spiritual" spouse who, in order to be appeased, requires the creation of a shrine in the personal hut of the individual. A man will own his spouse, the blob bian, and a woman her spouse, the blob bla, which they carry around everywhere they go. Politically, the bonuamuen protects the village from external threats; it obliges the woman to a certain discipline; and it appears at the commemorations of death of notables. When they intervene in the life of the community, they take the shape of a wooden helmet that represents a buffalo or antelope and which is worn with a raffia costume and metal ankle bracelets; the muzzle has teeth which incarnate the fierce animal that is to defend the group. Aesthetically and socially, the second mask is used at the funerals of women during the harvest season. It celebrates beauty and age, hence its refined features. The double mask represents the marriage of the sun and the moon or twins, whose birth is always a good sign. Socially also, the very characteristic, round-shaped "lunar" goli is surmounted by two horns. It was borrowed from the Wan for a celebration adopted by the Baule after 1900. Celebrating peace and joy, they would sing, dance, and drink palm wine. In the procession, the goli preceded the four groups of dancers, representing young adolescents. The goli would be used on the occasion of the new harvest, the visit of dignitaries, or at the funerals of notables. The foundation of Baule social and political institutions is the matrilineal lineage; each lineage has ceremonial stools that embody ancestral spirits. Paternal descent is recognized, however,
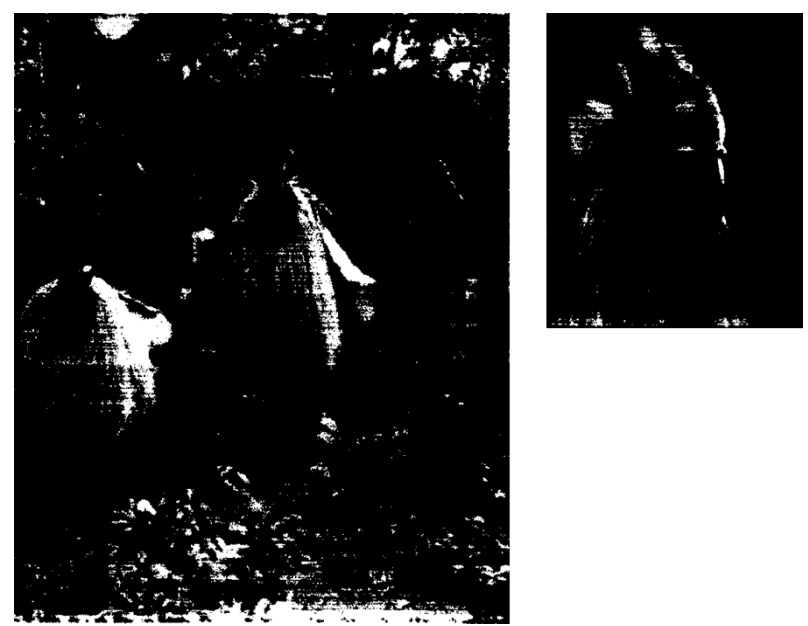

Figure 2. A Baule mask for use in entertaining dignitaries. 
and certain spiritual and personal qualities are believed to be inherited through it. The Baule believe in an intangible and inaccessible creator god, Nyamien. Asie, the god of the earth, controls humans and animals. The spirits, or amuen, are endowed with supernatural powers. Thus the bonuamuen masks represented this belief. Religion is founded upon the idea of death and the immortality of the soul. Ancestors are the object of worship but are not depicted (Bacquet, 2002). The Baule masks, when depicting human features, are feminine in nature because of the origins of the masks. Queen Aba Pokou and her descendants led her people until the 19th century. The queendom disintegrated due to internal conflicts and by the beginning of the 20th century, when the French colonials arrived, they found only a network of villages, headed by councils of venerated men.

\subsection{The Mossi Masks}

The Mossi are mainly farmers who live in the central part of the country. They are organized into four centralized Mossi kingdoms: Yatenga, Ouagadougou, Tenkodogo, and Fada N’Gourma. Ouagadougou, under its leader, the moghonaba, is the most important. The power of the king in Mossi kingdoms is exercised through a court and extends over the many lesser chiefs in charge of tightly knit districts and villages. The village earth priest directs the religious life, which centers on ancestor worship, and serves as a leader complementary to the village chief. The kings are at the top of the religious hierarchy, serving as the mediums for attracting supernatural powers to promote the welfare of the people. The Mossi are the largest tribe living in Burkina Faso, with more than 2 million people. They live mainly on the central plateau of Burkina Faso. They cultivate millet and cotton, and rear cattle in the northern savannah regions.

\subsubsection{The Mossi Masking Tradition}

The best known Mossi mask style is found in the north-western Mossi kingdom called Yatenga, an area once occupied by the Dogon. The masks (as shown in Figure 3) are vertically orientated, with a tall, slender plank that rises above the face of the mask and is decorated with red, white and black geometric patterns. The face of the Mossi mask is a concave oval, bisected vertically with a dentate ridge, the face painted white. Dogon masks are concave and rectangular, with a similar vertical ridge. Certain Dogon masks are surmounted by a vertical plank that is similar to the plank on Mossi masks from Yatenga. In addition, there are types, such as the mask surmounted by a female figure, that occur among both groups and are stylistically related.

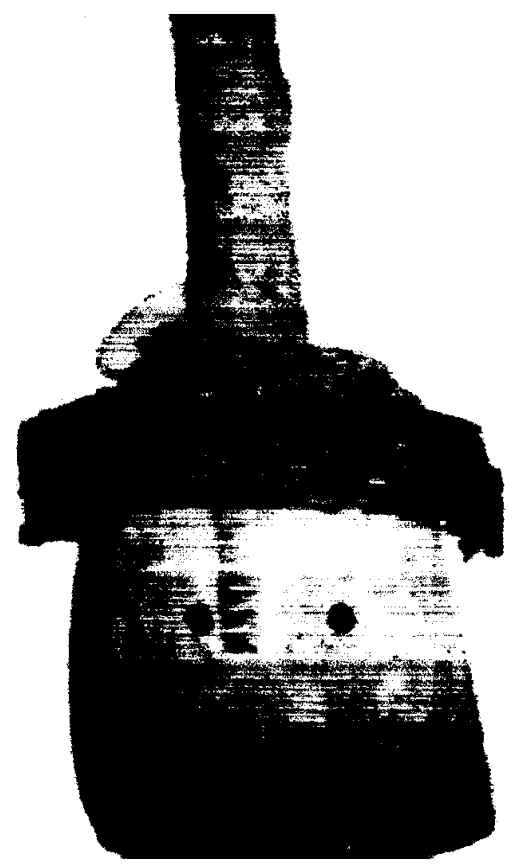

Figure 3. Wooden, facial portion of a wan-zegamask of the Mossi people living in the Boulsa of Burkina Faso. 
In other northern areas to the east of Yatenga, groups of Kurumba were conquered and assimilated into Mossi society. The masks of their nyonyose descendants include the same oval, convex face and complex plank that appear on southern Kurumba masks. Geometric patterns are painted roughly, just as they are among the $\mathrm{Ku}-$ rumba who live to the north. When masks are not being worn in performances they are placed on ancestral shrines in the kimseroogo, or ancestral spirit house of the family that owns them. Sacrifices may be made on the mask to obtain the blessings of the spirit that the mask represents. Men and women, adults and children alike have access to the masks for sacrifice, although all sacrifices are administered by a man (Roy, 1996).

\subsubsection{Functions}

Mossi masks play a fundamental role because they are the reincarnation of the animal totem, the spirits of the important dead elders, and of the collective spirits of the ancestors of the clan. In the south west (Ouagadougou style) and in the north (styles of Yatenga, Risiam and Kaya), each male head of a Tengabisi lineage may own a mask, in the form of the clan's totemic animal, on which he and his family may make sacrifices to the spirits of the ancestors. These personal or lineage masks are kept in the spirit house of the lineage or in the owner's own house. The oldest mask is referred to as the wan-kasenga, or "big mask", the chief mask at all funerals and year-end sacrifices. The remaining masks of the clan, almost identical in form to the senior mask, are referred to collectively as wan-huh, or "bird masks". This does not mean that these masks represent birds in form, but refers to their function at funerals and other mask appearances as agents for crowd control. In the east (Boulsa) this function is performed by the large, red wan zega. The major masks of each clan appear much less frequently than do the other, less important masks. Wan-kasenga rarely travel to other villages to appear at the funerals of clan members who have moved away from the primary clan residence. Masks appear at burials, and at funerals of clan elders. They protect and aid the members of the clan, and they protect the harvest of wild-growing fruits. And they are portable altars on which the blood of animals may be offered as sacrifices to the ancestors of the clan. The spirits protect the family from disease, accident and natural disaster, its crops from insects and drought, its women from infertility, and generally ensure success in life. Finally, Mossi masks appear most frequently at funerals, when masks that belong to the clan of the deceased appear to honour the dead and to participate in the blood sacrifices that free the spirit of the dead to leave the world of the living and travel to the world of the ancestral spirits (Roy, 1996).

\subsection{Central Africa}

The Kuba masks and the Kifwebe masks of Zaire will be examined.

\subsubsection{The Kuba Masks}

Kuba is a kingdom located between the Kasai, Sankuru and Lulua rivers in the region of West Kasai, ZaIre. In a strict sense, "Kuba art" refers to the arts of the Kuba kingdom; there is no relationship between style and ethnic grouping. In a wider sense, "Kuba art" includes the arts of neighbouring peoples whose artistic works are similar to those produced within the Kuba kingdom. Such peoples include the Lele and Wongo beyond the Kasai River to the west; the Biombo between the Kasai and Lulua rivers; the Ooli, Ekolombi and other small groups north of the River Sankuru; as well as the Ndengese across the Lokenye River and the Binji to the east.

\subsubsection{Kuba Masking Tradition}

Three royal mask types exist: the tailored MwaashaMbooy, representing Woot and the king; the wooden face mask, NgadyMwaashaMbooy, the incestuous sister-wife of Woot; and the wooden helmet mask, Bwoom, the commoner. All wooden Kuba masks clearly belong to a single style. The oldest one, Bwoom, represents the nature spirit Ngesh, Pygmy or Commoner depending on the context. It often forms part of a group including one depicting the ancestor of mankind, MwaashaMbooy and his sister, NgadyaMwaash. Beyond these, a dozen other mask types exist, associated with initiation and representing such figures as Lord, Mother, Wise Man, Elephant, Ram and Antelope. Masks were also used at funerals and at the royal dancing-play, flu!, in which King, MwaashaMbooy, and Commoner, Bwoom, fought over Woman, NgadyaMwaash. In addition to the wooden masks, a set made in fibre and netting represented Servant of Initiation, Snake and Antelope and perhaps some others. A study of mask types, their nomenclature and their iconography is still needed. Regional variability is important here. The Bushong at the capital, the Bushong and the Kete in the south of the country, the Pyang, the eastern 
Kuba, the Biombo and perhaps some of the other Kuba groups had their own initiation rituals and their own masks and icons (see Figure 4). Among the Bulang and Kete in the south of the country some tall masks representing the whole bodies of ancestresses or spirits were also in use (Cornet, 1972).

\subsubsection{Functions}

Religion was less a focus for visual art than was the political organization. The royal enthronement costume assimilated the badges of all ranks, but it also included elements proper only to the king. The royal anvil was a symbol of the legitimacy of kingship and its links to the supernatural. The royal funerals and installations, using a mass of visual symbols, including the mask NshoaMwaashaMbooy, emphasized the uniqueness and the continuity of kingship as well as its relation to the administration. Praised as "God on Earth", the king, nyim, is a divine ruler who controls fertility and communicates with the creator, Mboom. Kuba masks primarily address status, prestige, and the court; they are manifestations of social and political hierarchy. Rank and wealth are expressed in extensive displays of regalia: jewelry, rich garments of embroidered raflia cloth, ceremonial knives, swords, drums, and elaborated utilitarian items. Bwoom masks are amongst the most important objects to their culture. They are used by the society of sorcerers who call upon primordial ancestors for purposes of social control. Taking hallucinogens was part of these ceremonies and during the ensuing trance information was revealed. This served the Kuba as one of major methods of divination. This mask gives the courtly angles of the king masks a profundity by relationship and its helmet nature with enlarged head in most styles suggests a hydrocephalic man or pygmy who came before everyone else did (Cornet, 1972).

\subsubsection{The Kifwebe Masks}

Kifwebe masks are the most popular masks created by the Songye tribe of Zaire and are worn in connection with the BwadiBwaKifwebe secret society. Kifwebe means "mask" in the Songye language. The size of the crest determines the magical power of the mask. During initiation, circumcision or funeral ceremonies, a dancer will wear the mask and his body will be covered with straw. The dancer who wears the male mask will display aggressive and uncontrolled behavior with the aim of encouraging social conformity, whereas the dancer who wears the female mask displays more gentle and controlled movements and is assumed to be associated with reproduction ceremonies.

\subsubsection{Kifwebe Masking Tradition}

Kifwebe are made out of wood and come in many shapes and sizes, depending on the area where they were made or their function. Basically, the masks (see Figure 5) made to be worn come in male, female, or youngster versions, the females usually are white and have no crest, the males are polychrome and will have a crest.

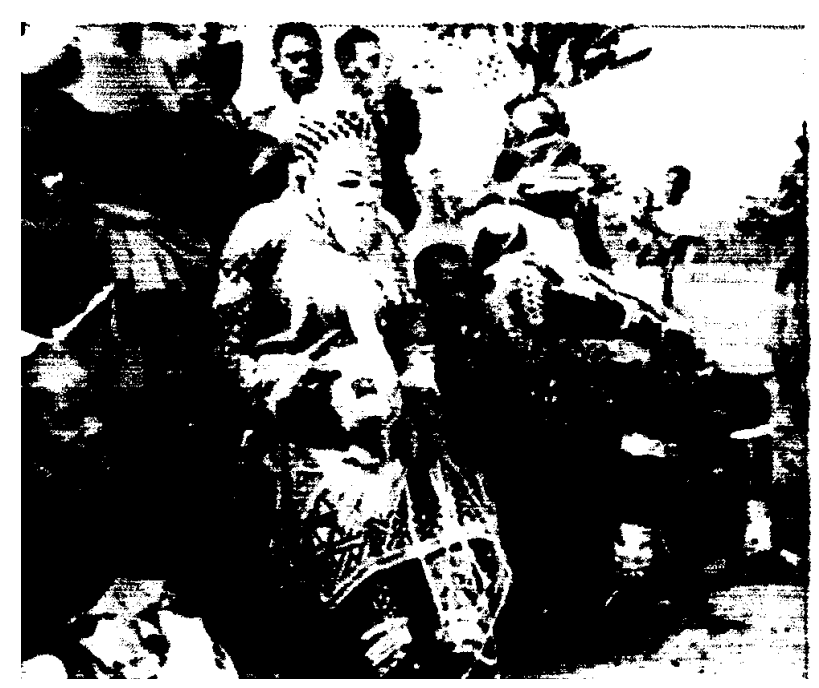

Figure 4. Kuba masquerades in sitting mode. L-R: NgadyMwaashaMbooy, the incestuous sister-wife of Woot and MwaashaMbooy, representing Woot and the king. 


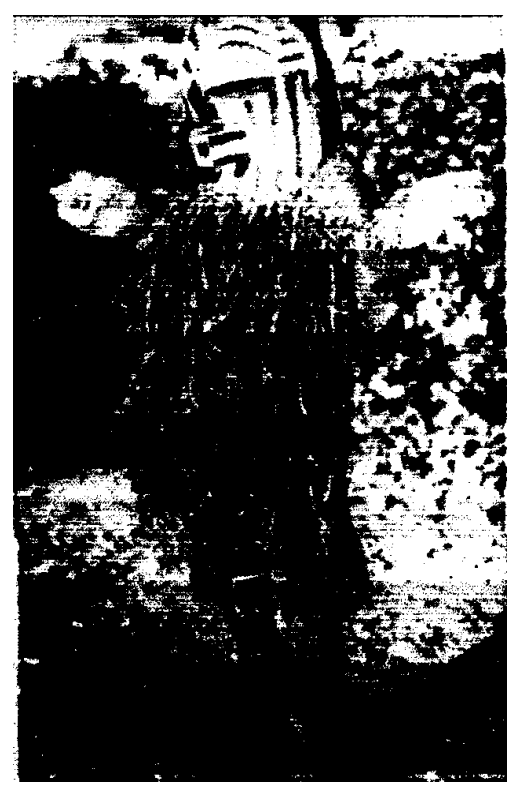

Figure 5. Kifwebe masquerade poses for a shot.

When masks are worn they are part of a complete costume consisting of a hood attached to the mask, a shirt and pants made from woven bark. The soles of his shoes will be elephant skin and a striped fur belt completes the costume. The top of the mask will have attached to the hood a plummet and a fibre beard will circle the masks face. The mask-wearer will carry in his hands items allowing to further identify the portrayed character such as a staff, knife, stick or twigs. Other masks are made to be hung in meeting houses; these are sometimes affixed to a plaque (Bassani, 2005).

\subsubsection{Functions}

Among the Songye, Kifwebe masks are used for a variety of occasions. Groups of mask-wearers go from compound to compound to collect donations for their association, the masks are also used during initiation procedures worn by the leader of the initiation, by initiators, by circumcisers, by the guardians of the circumcision camp. To celebrate seasonal events such as new moon, seeding of crops, first harvesting, first rain. To enforce social control policing, levying of taxes and fines, rendering of justice, execution. To educate and instruct maskwearers in stage plays depicting the social do's and don'ts. To act as a mnemonic and moralistic device when maskers re-enact mythical or historical events from the past, or stage moralistic folktales based on animal and human characters. To honor the deceased at funeral ceremonies, maskers accompany and honor important members of society either at funerals or funeral commemorations. To sanctify nominations of titleholders, ritual specialist and enthronement of chiefs. To supervise communal duties such as ditch-cleaning, fortification, road and bridge building. The masks are also used during gathering of associations worn during meeting of members of brotherhoods, associations and societies (Bassam, 2005).

\section{East Africa}

The Lipiko masks of Tanzania and the Chokwe masks of Mozambique (spreading from Angola in Central Africa) will be examined:

\subsection{Lipiko Masks}

The Makonde of northern Mozambique and southern Tanzania wore helmet masks for initiation ceremonies called Lipiko for both boys and girls. The mask or "head of the lipiko" (mutiwalipiko) is made of a light, balsalike wood and worn with a cloth tied around the bottom rim that falls loosely over the masquerader. The naturalism of these masks is often accentuated by the addition of human hair. 


\subsection{The Lipiko Masking Tradition}

The male and female masks were used to celebrate the emergence of young women from initiation camps. The masks (see Figure 6) stand up two and two, each pair facing the other, and begin the same series of movements. The masks are of wood, two of them representing men, and two women. This is evident a hundred paces off from the prominence give to the Pelele [lip labret], whose white stands out with great effect from the rigid black surface (Weule, 1909: p. 235). Makonde artists add to the naturalism of their carvings by using beeswax and human hair to represent scarification patterns and fashionable hairstyles. Many of the female masks include the large lip labrets that Makonde women used to wear.

\subsection{Functions}

Jorge and Margot Dias have studied the Makonde over the past thirty years and indicate that masks are worn in mapiko dances associated with the initiation of both men and women. Initiation includes instruction in the skills of adulthood, as well as in Makonde dances, songs, and the costumes and secrets of the mapiko masks. The initiates are told that the masks are not the spirits of the dead, but are worn by living men, and after a period of training in dance, they wear the masks in a great festival at the center of the village. The masks may also appear during an ngoma ceremony in which adolescents are taught about marriage and the demands of adult family life.

\subsection{Chokwe Masks}

The Chokwe, Lwena, Songo and Ovimbundu are farmers, hunters and small-scale pastoralists. Their society is matrilineal, with inheritance passing from uncle to uterine nephew.

Chikungu's face is modelled in resin. For the Mukanda initiation rites, there is the Chikunza, the patron of the boys' camp. Its name refers to the grasshopper, while its tall, conical and ringed helmet refers to the horns of the roan antelope. There is also the Chihongo.

\subsection{Chokwe Mask Functions}

Chokwe masks draw in their symbolism on aspects of nature which identify different masking traditions traceable to the Chokwe. The Chokwe draw their features from both the Chihongo, Chikungu, Chikunza and the Pwo masking traditions. Their role is to govern the different phases of the ritual and to keep the female world at a distance (as shown in Figure 7). Chihongo levied a sort of tribute and took part in judicial matters. Pwo, the female mask, evokes the ancestor of the lineage associated with fertility. Representing the feminine ideal, the dancer teaches women graceflul manners and refined attitudes and gestures. Chikungu sacred mask is worn by the chief for his investiture and at a ceremony during which he makes propitiatory sacrifices to the dynastic ancestors, seeking their blessings for the well-being of the community. Chikunza represents a benevolent spirit responsible for fertility and the hunt.

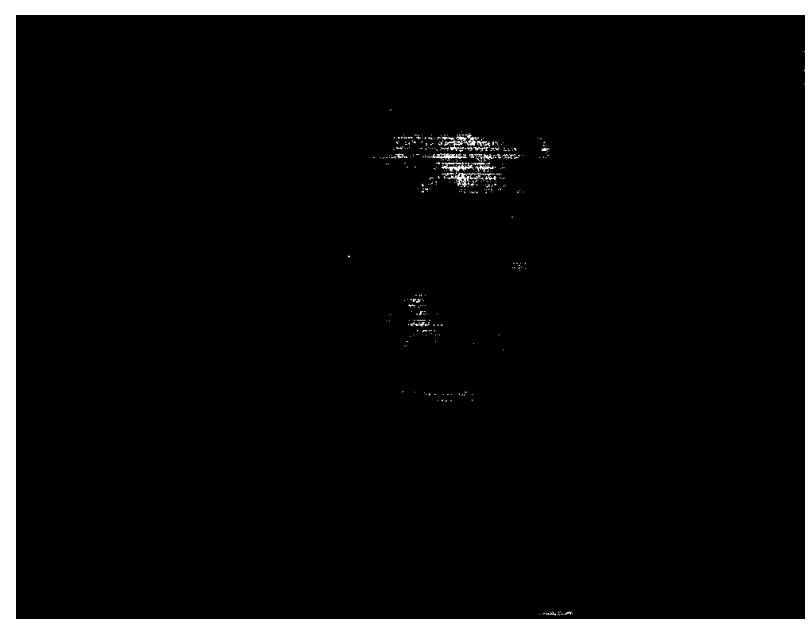

Figure 6. Lipiko in an inactive mode. 


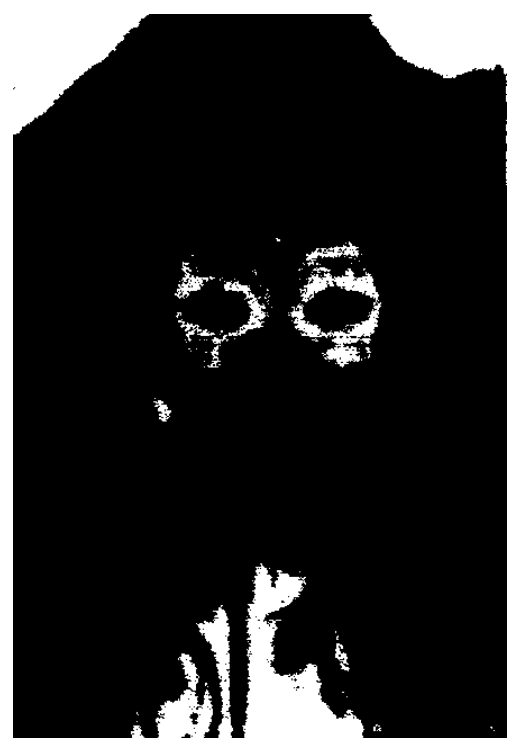

Figure 7. Chokwe masquerwk.

\section{Conclusion}

This study is on masking traditions of West, East and Central Africa with a view to understanding and appreciating their functions in their base societies. The masking traditions of The Baule masks of Cote d'Ivoire and the Mossi masks of Burkina Faso are examined in the area of West Africa. The Lipiko masks of Tanzania and the Chokwe masks of Mozambique (spreading from Angola in Central Africa), both of East Africa are studied. And in researching Central Africa, the Kuba masks and the Kifwebe masks of Zaire are examined. We gather that there is a preponderance of ancestral consciousness in all of the masks studied. For example, Mossi masks appear most frequently at funerals. Kuba masks are used by sorcerers to call upon primordial ancestors for purposes of social control. Kifwebe masks were used to honor the deceased at funerary ceremonies; maskers accompany and honor important members of society either at funerals or funeral commemorations. Lipiko masks are associated with the initiation of both men and women. And the Chikungu sacred mask, a type of Chokwe masks, is worn by the chief for his investiture and at a ceremony during which he makes propitiatory sacrifices to the dynastic ancestors, seeking their blessings for the well-being of the community. These functions of masking traditions reveal the desire to enforce law and bring about order in the society. They show that the role of the masquerade is within the same purview as the police of today and the involvement of spiritual "realities" bring about fear and reverence.

\section{References}

Bacquet, J.-B. (2002). The Tribal Arts of Africa. London: Thames \& Hudson.

Bassani, E. (2005). Arts of Africa: 7000 Years of African Art. Milan: Skira Editore.

Cole, H. M. (1985). I Am Not Myself. The Art of African Masquerade. Los Angeles: Museum of Cultural History, University of California at Los Angeles.

Cornet, J. (1972). Preface in J.D. Mobutu's. Art d'Afrique noire au pays dufleuve Zaire. Brussel: Arcade.

Ejizu, C. I. (1986). OFO, Igbo Ritual Symbol. Enugu: Fourth Dimension Publishers Ltd.

Jacques, K., Jean-Louis, P., \& Lucien, S. (1988). L'art Ct les grandes civilizations: L'artafricain. Paris: Editions Mazenod, 620.

Lange, D. (2005). Die N'tomobei den Bambara und in Ugarit (Syrien). EmBeitrag der Ethnologiezur Altorientalistik. In K. Geisenhainer, \& K. Lange (Eds.), Bewegliche Horizonte (pp. 265-282). Festschrift fir Benthard Streck, Leipzig: Universitätsverlag.

Nketia, K. (2012). Safeguarding Traditional Culture and Folklore in Africa. Ghana: International Centre for African Music and Dance, University of Ghana School of Performing Arts Accra. http://www.folklife.si.edu/resources/unesco/nketia.htm.Produced 
Nunley, J. W. (1996). Cover Story. Journal of the American Medical Association, 276, 1782. http://dx.doi.org/10.1001/jama.1996.03540220006002

Obiechina, E. (1978). Literature-Traditional and Modern-in the Nsukka Environment. In Ofomata, G. E. K. (Ed.), The Nsukka Environment. Enugu: Fourth Dimension Publishers.

Roy, C. (1996). The Art of Burkina Faso. Canberra: Mangold Publishers.

Schaedler, K. (1992). Gods Spirits Ancestors: African Sculpture from Private German Collections. Villa Stuck Munchen: Panterra, 47. 